\title{
Menggaet Lebih Banyak Tamu Francophones: Pembelajaran Bahasa Prancis bagi Warga dan Karyawan Kampung Homestay Borobudur
}

\author{
B.R. Suryo Baskoro', Hayatul Cholsy \\ Prodi Sastra Prancis, Fakultas Ilmu Budaya, Universitas Gadjah Mada \\ 'Pos-el: suryobaskoro@ugm.ac.id \\ 2Pos-el: hayatulcholsy@ugm.ac.id
}

Tim Pengabdian kepada Masyarakat:

Sajarwa, B.R. Suryo Baskoro, Hayatul Cholsy, Wening Udasmoro, Ali Shahab, Subiyantoro, Wiwid Nurwidyohening, Cartalyna Napitupulu, Aprillia Firmonasari, Wulan Tri Astuti, Siti Rahayu

\begin{abstract}
Learning French for residents and homestay employees in the homestay village, Dusun Ngaran, Desa Borobudur is carried out by the French Literature Study Program, Faculty of Cultural Sciences, UGM as a community service activity in 2018. This learning is a follow-up of French language training for homestay owners who have done in 2017. Using a tutorial system in small groups and communicative approaches, residents and homestay employees have been able and feel confident in greeting, offering, explaining, giving choices, and other verbal activities related to guests or potential guests in French (francophones) through simple communicative expressions. Simple French language skills are a powerful capital to attract more francophones guests to visit the homestays. The support of French Literature Study Program on tourism development in Borobudur Homestay Village was also given in the form of assistance in promoting the region's tourism potential through refinement of French language pages and brochures. Thus, francophones tourists can find out more easily and more quickly their whereabouts and get to know the area in order to attract more tourists to stay at a homestay. Other results of this service are French language teaching materials in the form of text and documentary videos.
\end{abstract}

Keywords: learning materials, francophones, learning French, promotion

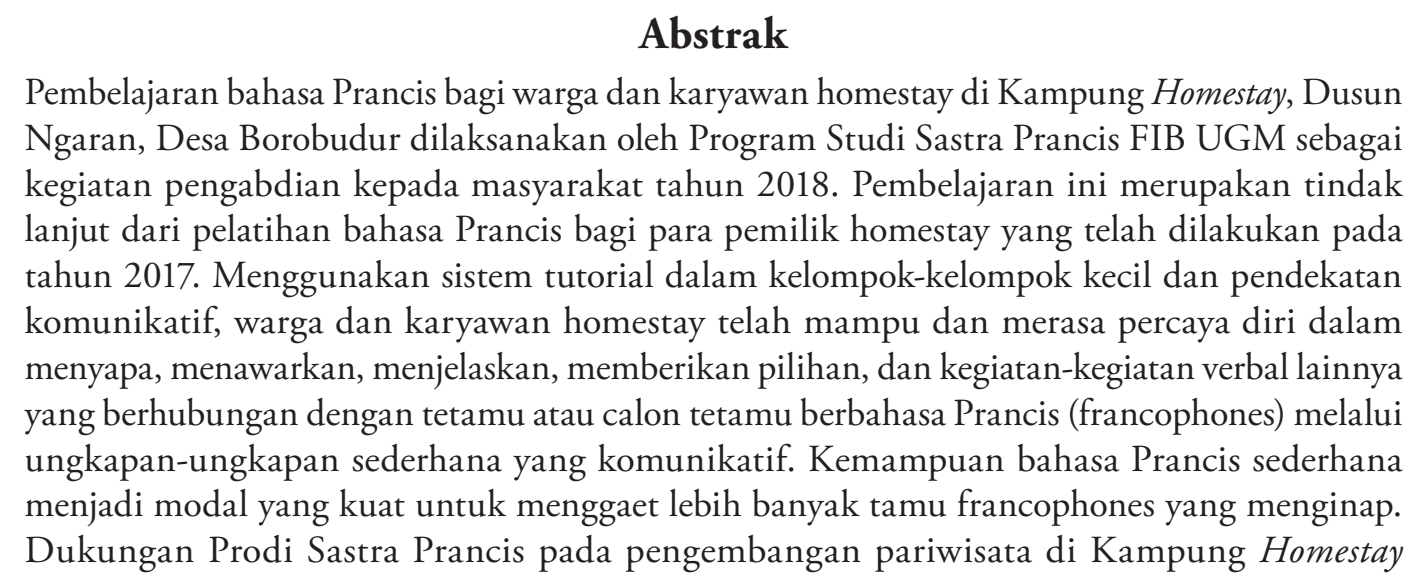


Borobudur juga diberikan dalam bentuk bantuan promosi potensi wisata kawasan tersebut melalui penyempurnaan laman dan brosur berbahasa Prancis. Dengan demikian, wisatawan francophones dapat lebih mudah dan lebih cepat mengetahui keberadaan serta mengenal kawasan ini, hingga kemudian tertarik untuk menginap di homestay. Hasil lain dari pengabdian ini adalah bahan ajar bahasa Prancis dalam bentuk teks dan video dokumenter.

Kata kunci: bahan ajar, francophones, pembelajaran bahasa Prancis, promosi

\section{Pendahuluan}

Jumlah wisatawan mancanegara (wisman) yang mengunjungi Indonesia sepanjang tahun 2017, menurut Badan Pusat Statitsik (BPS), adalah 14,03 juta orang. Angka ini meningkat 21,88 persen jika dibandingkan dengan tahun 2016 yang mencatat 11,51 juta kunjungan ${ }^{1}$. Dibandingkan dengan jumlah penduduk Indonesia pada tahun 2017, yakni hampir 258 juta $^{2}$, jumlah wisman adalah 5,4\% dari total populasi Indonesia. Angka ini masih sangat jauh jika dibandingkan dengan negara Prancis yang pada tahun 2017 berpenduduk 67,1 juta $^{3}$ dan dikunjungi oleh 89 juta wisman ${ }^{4}$ atau oleh $132 \%$ jumlah penduduknya.

Dalam hal situasi kepariwisataan, Indonesia sama sekali belum sebanding dengan Prancis, kecuali jika dibandingkan dengan negara-negara ASEAN. Namun demikian, setidaknya hal itu mengindikasikan bahwa masih ada banyak sekali hal yang perlu dilakukan dalam rangka mendongkrak jumlah kunjungan wisman ke Nusantara.

Wisman Prancis yang berkunjung ke Indonesia meningkat dari waktu ke waktu. Pada tahun 2017, wisman Prancis yang mengunjungi Bali tercatat 162.2885. Jika dilaporkan bahwa jumlah tersebut merupakan 40\% dari total wisman Prancis, jumlah wisman Prancis yang mengunjungi Indonesia pada tahun 2017 adalah lebih dari 405.000 orang. Angka ini cukup menjanjikan, apalagi ditambah dengan wisman dari negaranegara berbahasa Prancis (atau francophone), seperti Quebec, (sebagian besar) Belgia, (sebagian) Swiss, (sebagian) Polandia, atau Negara-negara seperti Maroko, Aljazair, dan Tunisia.

Jumlah wisman francophone tersebut cukup signifikan untuk dikelola dengan lebih baik, dalam rangka meningkatkan devisa negara dan mendukung perekonomian, mengiringi upaya-upaya promosi besar-besaran, perbaikan sarana-prasarana pariwisata, dan peningkatan kemampuan SDM bidang pariwisata yang terus menerus dilakukan oleh pemerintah.

Dalam upaya untuk mendukung program pemerintah di bidang peningkatan kemampuan SDM bidang pariwisata, Prodi Sastra Prancis Fakultas llmu Budaya Universitas Gadjah Mada (FIB-UGM) memiliki kepedulian untuk berpartisipasi dalam meningkatkan kesiapan SDM bidang pariwisata. Untuk itulah, Prodi Sastra Prancis

1 https://www.cnnindonesia.com/gaya-hidup/20180201163952-269-273237/indonesiadikunjungi-14-jutaan-turis-sepanjang-2017

2 https://tumoutounews.com/2017/08/25/download-jumlah-penduduk-dunia-tahun-2017/

3 https://fr. wikipedia.org/wiki/D\%C3\%A9mographie_d e_la_France

4 https://www.planetoscope.com/tourisme/415-nombre-de-touristes-en-france.html

5 https://ravel.kompas.com/read/2018/01/15/082900 827/semakin-banyak-turis-perancis-kebali-tahun- 2017 
mengadakan kegiatan pengabdian yang diberi tajuk "Menggaet Lebih Banyak Tamu Francophones: Pembelajaran Bahasa Prancis bagi Warga dan Karyawan Kampung Homestay Borobudur". Program pengabdian kepada masyarakat ini merupakan implementasi keilmuan Prodi Sastra Prancis dalam wujud pemberdayaan masyarakat yang sesuai dengan visi dan misi UGM. Pemberdayaan masyarakat yang dilakukan berupa pembelajaran bahasa Prancis bagi para warga dan karyawan homestay di kawasan Candi Borobudur. Selain dapat memberikan sumbangan yang cukup berarti dalam hal kepuasan wisman yang mengunjungi Candi Borobudur dan menginap di Kampung Homestay Borobudur (selanjutnya disingkat KHB), penguasaan bahasa Prancis sederhana dan komunikatif akan menjadi senjata yang ampuh dalam menggaet lebih banyak kunjungan wisman francophone. Selain pembelajaran bahasa Prancis, Prodi Sastra Prancis juga menyempurnakan isi atau informasi pada http://www.kampunghomestay. com/ dalam bahasa Prancis; demikian pula memperbaiki brosur berbahasa Prancis yang sudah dibuat oleh Prodi pada tahun 2017 agar kampung ini lebih dikenal, didengar, dan dilihat oleh semakin banyak wisman francophone.

KHB merupakan sebuah paguyuban yang diketuai oleh Bapak Muslich (45 tahun). Nama paguyuban tersebut melekat pada Dusun Ngaran, Desa Borobudur, Magelang, Jawa Tengah, yang berada tepat di sebelah Candi Borobudur-salah satu warisan dunia. Candi Borobudur adalah objek utama pariwisata di Jawa Tengah dan D.I. Yogyakarta, atau Indonesia pada umumnya, dengan jumlah pengunjung kurang lebih 3,5 juta per tahun. Di antara sejumlah wisman yang mengunjungi candi, tidak sedikit yang membutuhkan tempat penginapan. Potensi inilah yang digali oleh penduduk setempat hingga kemudian didirikanlah Paguyuban Homestay Borobudur. Paguyuban mendorong warga untuk memanfaatkan rumah-rumah mereka sebagai homestay. Pada saat paguyuban berdiri, yakni 23 September 2017, sejumlah 20 rumah sudah diubah menjadi homestay dengan jumlah kamar 70 unit. Pada Juli 2018, jumlah homestay meningkat menjadi 28 unit dengan total kamar sebanyak 111 kamar. Selain jumlah kamar yang banyak dan dapat memfasilitasi biro-biro perjalanan dalam penyediaan akomodasi, KHB juga telah menjalin kerja sama dengan berbagai pihak. Kerja sama dengan Punthuk Setumbu (lokasi untuk menikmati sunrise) diwujudkan dalam pemberian potongan harga $15 \%$ bagi grup dari KHB. Kerja sama yang bertujuan untuk memberikan fasilitas bagi tetamu sekaligus meningkatkan perekonomian warga lokal juga dilakukan dengan para pengrajin (gerabah, batik, dan kriya); komunitas mobil antik VW (untuk berkeliling desa wisata sekitar Borobudur); dan Delta Rafting ${ }^{6}$. Geliat KHB ini selaras dengan kebijakan pemerintah untuk mengembangkan pariwisata berbasis masyarakat. Community based tourism cocok dikembangkan di Indonesia, sebagaimana di banyak negara lain, mengingat dampak-dampak positifnya bagi pemberdayaan masyarakat, kolektivitas, perekonomian daerah, dan lingkungan (Goodwin dan Santilli, 2009:24-35).

Keberadaan paguyuban atau komunitas seperti KHB perlu didukung oleh semua pihak, tidak hanya oleh Pemerintah. Salah satu bentuk dukungan yang secara khusus diberikan oleh Prodi Sastra Prancis FIB UGM ialah memberikan pembelajaran bahasa Prancis kepada warga dan para karyawan homestay yang semuanya adalah anggota paguyuban.

Pembelajaran bahasa Prancis bagi warga dan karyawan homestay KHB merupakan

6 Hasil wawancara dengan Bapak Muslich, Ketua Paguyuban Kampung Homestay Borobudur. 
strategi yang bagus dalam kerangka hospitality, khususnya bagi tetamu francophones. Layanan berbahasa Prancis diyakini akan berdampak positif bagi tetamu francophones, yakni mereka akan merasa akrab dengan penduduk setempat, hingga kemudian berminat untuk menginap di homestay yang bertebaran di seluruh Dusun Ngaran.

Pembelajaran bahasa Prancis yang diberikan kepada para warga dan karyawan homestay KHB adalah pembelajaran yang berbasis budaya. Hal ini merupakan sebuah keniscayaan, mengingat bahasa dan budaya adalah dua aspek yang tak terpisahkan. Bahasa tanpa budaya adalah sesuatu yang tidak terbayangkan, demikian juga budaya manusia tanpa bahasa. Bahasa adalah cermin budaya (Choudhury, 2014:3). Dalam kerangka pemahaman dan kenyataan tersebut, program pembelajaran bahasa Prancis dilakukan dengan pendekatan budaya Prancis atau budaya francophone. Pendekatan ini penting dilakukan, mengingat budaya Prancis berbeda dengan budaya Indonesia (termasuk Jawa). Dalam konteks sapaan pada pertemuan pertama atau basa basi pada budaya Indonesia, misalnya, pertanyaan semacam "Berapa usia Anda?" mungkin merupakan hal yang biasa. Akan tetapi, dalam budaya Prancis, pertanyaan seperti itu merupakan pertanyaan yang bersifat personal sehingga kurang tepat jika diajukan dalam konteks sapaan jika kedua peserta komunikasi belum akrab. Dengan pendekatan yang bersifat kultural tersebut diharapkan para pembelajar memahami dan menyadari perbedaan kultural antara Indonesia dan Prancis. Dengan demikian, mereka mampu mengujarkan sapaan atau pertanyaan yang lebih tepat, yang pada gilirannya akan mendatangkan rasa hormat dari francophone terhadap warga.

Latar belakang kultural dan potensi ke depan yang dipaparkan di muka menjadikan program pembelajaran bahasa Prancis bagi para warga dan karyawan homestay di KHB strategis untuk dilaksanakan. Para warga dan karyawan homestay yang merupakan para pelaku pariwisata diberi pembelajaran berkomunikasi dengan wisatawan francophone. Didukung oleh pengetahuan mereka tentang Candi Borobudur dan kekhasan-kekhasan lokal, kemampuan berbahasa Prancis sederhana diharapkan mampu menggaet lebih banyak lagi tetamu francophones, khususnya untuk menginap (lebih lama) di KHB.

Kegiatan pengabdian "Menggaet Lebih Banyak Tamu Francophones: Pembelajaran Bahasa Prancis bagi Warga dan Karyawan Kampung Homestay Borobudur” ini dilakukan dengan tujuan menghasilkan hal-hal berikut.

- kemampuan berbahasa Prancis sederhana oleh warga dan karyawan homestay, sebagai pelaku pariwisata, dalam rangka menggaet lebih banyak wisman francophones untuk menginap

- pembaharuan dan perbaikan laman dan brosur KHB berbahasa Prancis

- bahan ajar dan video tutorial mengenai bahasa Prancis pariwisata

Kegiatan pengabdian ini diyakini akan memberi dampak yang positif pada aspek hospitality penduduk setempat. Dengan kemampuan berkomunikasi dalam bahasa Prancis sederhana, para wisman francophones akan merasa lebih dihargai-rasa yang akan menjadikan mereka lebih kerasan sehingga timbul keinginan untuk tinggal lebih lama di kawasan Borobudur. Jika semakin banyak wisman, khususnya francophones yang menginap, hal ini akan mengangkat perekonomian lokal. Publikasi mengenai keberadaan KHB melalui laman dan brosur berbahasa Prancis juga akan meningkatkan jumlah francophones yang mengenali Borobudur dan fasilitas inapnya. 


\section{Metode Pelaksanaan Pengabdian}

Dalam upaya untuk memberikan materi pembelajaran yang sesuai dengan kebutuhan, terlebih dahulu dilakukan survei. Hasil survei memperlihatkan bahwa pelaku pariwisata di KHB membutuhkan pembelajaran bahasa Prancis yang ditujukan khusus kepada para warga dan karyawan homestay ${ }^{7}$, serta penyempurnaan materi untuk laman dan brosur. Berdasarkan hasil survei tersebut, Prodi Sastra Prancis FIB UGM kemudian menyusun materi pembelajaran bahasa Prancis yang menjawab kebutuhan, yakni penerimaan tamu penginapan dan sapaan-sapaan sederhana. Di samping pembelajaran, Prodi juga akan memperbaiki dan menyempurnakan laman dan brosur berbahasa Prancis mengenai KHB. Pembelajaran menggunakan sistem tutorial dengan metode pembelajaran komunikatif.

\section{Hasil dan Pembahasan}

Pengabdian kepada masyarakat ini mendapat dukungan dari perangkat desa dan memperoleh tanggapan positif dari warga, khususnya warga dan karyawan homestay KHB Dusun Ngaran, Desa Borobudur, Magelang. Para peserta menikmati proses pembelajaran dan dengan bersemangat melatih sapaan-sapaan serta kalimat-kalimat sederhana bahasa Prancis yang diajarkan. Kemajuan yang dicapai sangat pesat. Pada mulanya, mereka sama sekali tidak mengenal bahasa Prancis.

Setelah melalui proses pembelajaran, mereka rajin mempraktikkan kalimat-kalimat yang diajarkan oleh para tutor. Dengan pendekatan yang komunikatif dan kekeluargaan, para pembelajar tidak malu-malu untuk mengungkapkan bahkan berdiskusi sederhana dengan tutor dalam bahasa Prancis. Pendekatan seperti itu terbukti membuat para pembelajar percaya diri untuk berkomunikasi dalam bahasa Prancis. Program pengabdian yang dilakukan diharapkan dapat memberikan nilai tambah pada keberadaan KHB. Dampak nilai tambah yang diharapkan adalah meningkatnya jumlah wisman, khususnya francophones, yang menginap di Dusun Ngaran yang pada akhirnya akan meningkatkan taraf hidup warga setempat.

Kegiatan-kegiatan yang dilakukan pada program pengabdian ini berupa survei, pembuatan bahan ajar, pelatihan pembuatan video dokumenter, pelaksanaan pembelajaran, dan pembuatan video dokumenter kegiatan, yang masing-masing dipaparkan di bawah ini.

\section{Survei}

Agar program tepat sasaran, dilakukan survei terlebih dahulu ke Dusun Ngaran, Desa Borobudur. Survei ini dilakukan pada 14 Februari 2018. Survei terutama dilakukan dengan mengadakan pertemuan dan diskusi dengan Bapak Muslich (45 tahun), Ketua Paguyuban KHB. Diskusi tersebut menghasilkan kesimpulan bahwa pembelajaran bahasa Prancis kali ini difokuskan pada para warga dan karyawan homestay yang menjadi anggota KHB. Pada program pengabdian tahun 2017 yang lalu, pembelajaran diberikan kepada para pengelola homestay. Diskusi juga menghasilkan informasi mengenai kebutuhan materi peserta, jumlah peserta yang akan berpartisipasi, lokasi

7 Pada tahun 2017, pelatihan diperuntukkan bagi para pengelola homestay di KHB. 
pembelajaran, di samping sosialisasi mengenai metode dan materi pembelajaran yang akan diberikan. Diskusi tersebut menjadi penting karena menentukan apa yang dikerjakan oleh Prodi agar hasil yang dicapai dapat maksimal. Survei juga dilakukan pada calon lokasi pembelajaran dan lingkungannya, dalam rangka pembuatan video dokumenter. Pelaksanaan pendokumentasian diharapkan berjalan lancar karena tim sudah mengetahui dan mengenali titik-titik yang terbaik untuk keperluan tersebut. Survei juga dilaksanakan dengan mengevaluasi materi/isi laman dan brosur berbahasa Prancis mengenai KHB yang sudah dirintis pada tahun 2017 oleh Prodi.

\section{Pembuatan Bahan Ajar}

Bahan ajar yang dipergunakan dalam pembelajaran bahasa Prancis untuk warga dan karyawan homestay di KHB dibuat berdasarkan hasil survei yang telah dilakukan dan pendekatan kultural dalam pembelajaran bahasa asing. Dengan pendekatan kultural, bahan ajar yang dirancang diwarnai dengan sapaan-sapaan atau kalimat-kalimat sederhana yang sesuai dengan budaya atau kebiasaan-kebiasaan francophones. Metode pembelajaran dalam bahan ajar ini adalah metode komunikatif yang memfokuskan fungsi komunikatif bahasa. Artinya, bahan ajar tidak berisi pengenalan terhadap struktur (bahasa Prancis) yang lebih rumit daripada bahasa Indonesia, tetapi berisi ungkapanungkapan dalam memperkenalkan diri, menyapa, bertanya, menawarkan sesuatu kepada tetamu francophones, baik yang terkait dengan penginapan, fasilitas, transportasi, makanan, maupun percakapan-percakapan sederhana. Kalimat-kalimat yang diberikan merupakan kalimat yang sederhana dan mudah diucapkan seperti di bawah.

Touriste : Excusez-moi.

(Permisi..)

Employée : Bonjour, Madame. Qu'est-ce que je peux faire pour vous?

(Selamat pagi, Bu. Ada yang bisa saya bantu?)

Touriste : Je voudrais une boisson, l'eau minérale.

(Saya ingin minuman, air minerai)

Employée : Bien sûr, Madame.

(Tentu saja, Madame.)

Touriste : Où est le marché ?

(Di mana pasarnya ?)

Employée : Là bas, au coin de la rue.

(Di sana, di pojokjalan.)

Touriste : D'accord, merci.

(Baiklah, terima kasih)

Employée : Je vous en prie.

(Sama-sama)

\section{Pelatihan Pembuatan Video Dokumenter}

Dalam upaya untuk menghasilkan video dokumenter kegiatan yang representatif, dilakukan pelatihan bagi tim mahasiswa yang diberi tugas mendokumentasikan kegiatan pengabdian. Tim beranggotakan mahasiswa Prodi Sastra Prancis yang memiliki ketertarikan dan minat pada pembuatan video dokumenter. Pada pelatihan ini, tim 
mahasiswa mempelajari tahapan-tahapan prapengambilan gambar, pengambilan gambar, dan pascapengambilan gambar. Pelatihan ini diberikan oleh Teguh Supriyadi, jurnalis senior CNN Indonesia yang telah berpengalaman dalam membuat video dokumenter dan berpengalaman sebagai pemateri dalam berbagai pelatihan pembuatan video dokumenter.

\section{Pelaksanaan Pembelajaran Bahasa Prancis}

Pembelajaran bahasa Prancis bagi warga dan karyawan homestay di KHB dilakukan selama dua hari, yakni pada 10-11 April 2018. Kegiatan dilaksanakan di pendopo Warung Kopi Borobudur, Dusun Ngaran, Borobudur. Kompleks warung kopi ini merupakan salah satu Balkondes (Balai Ekonomi Pedesaan) Taman Wisata Candi yang dibangun di seluruh Kecamatan Borobudur. Balkondes yang rata-rata dibangun oleh BUMN mitra dimaksudkan untuk menampung dan menumbuhkan kegiatan ekonomi penduduk setempat. Pembelajaran ini diikuti oleh 35 orang peserta, yakni warga dan karyawan beberapa homestay dalam naungan KHB di Dusun Ngaran, Desa Borobudur. Proses pembelajaran diperkuat oleh para tutor yang adalah mahasiswa Sastra Prancis (minimal semester 5) yang diseleksi dan yang telah berpengalaman dalam tutorial bahasa Prancis.

Metode pembelajaran yang diterapkan pada program pengabdian kali ini adalah pendekatan komunikatif-personal yang diaplikasikan dalam tutorial pada 8 kelompok kecil yang masing-masingnya terdiri atas $5-7$ orang. Setiap kelompok dikelola oleh dua orang tutor dan disupervisi oleh satu orang dosen. Pembelajaran dengan model kelompok-kelompok kecil ini menjadikan proses pembelajaran berjalan lebih intensif sehingga membuahkan hasil seperti yang diharapkan. Pembelajaran yang diberikan adalah bahasa Prancis yang berbasis budaya Prancis. Pendekatan kultural ini penting dilakukan agar para pembelajar mengetahui pula kebiasaan-kebiasaan para penutur bahasa Prancis. Nilai kultural tersebut biasanya tecermin pada sapaan awal atau pada saat pertama kali bertemu. Contoh di bawah ini diberikan kepada peserta dan kemudian didiskusikan.

(1).

Karyawan : Bonjour Madame. Bonne journée.

(Selamat pagi Madame. Semoga hari ini menyenangkan)

Wisman : Bonjour. Également

(Selamat pagi. Anda juga).

(2).

Karyawan : Bonjour Madame.*Vous allez où?

(Selamat pagi Madame. Akan pergi ke mana?)

Diinformasikan kepada peserta bahwa tanda * pada percakapan (2) di atas menandai bahwa pertanyaan itu kurang pantas diujarkan pada saat pertama kali bertemu dengan seorang francophone. Pada budaya Indonesia, pertanyaan seperti itu mungkin dianggap wajar dan menjadi bagian dari basa-basi (artinya, cukup dijawab dengan Quelque part 'sebuah tempat'), namun dalam budaya francophone, pertanyaan semacam itu menjadi pertanyaan yang bersifat personal. Pertanyaan atau kalimat yang bernuansa personal hanya dapat diujarkan jika kedua peserta dalam komunikasi memiliki hubungan yang 
cukup akrab. Kesadaran terhadap perbedaan kultural ini penting diberikan dalam proses pembelajaran agar komunikasi dan interaksi dengan wisman francophone dapat lebih terjamin kelancarannya.

Proses pembelajaran berjalan dengan menyenangkan, terutama bagi para tutor. Hal ini karena antusiasme peserta yang tinggi dalam mengikuti setiap tahap yang diajarkan. Salah satu masalah yang cukup menonjol dalam belajar bahasa Prancis adalah mengenai lafal. Pada awalnya, para peserta mengalami kesulitan. Namun demikian, dengan bimbingan tutor, para peserta akhirnya mampu melafalkan sapaan-sapaan bahasa Prancis dengan cukup tepat dan setidaknya dapat dipahami oleh francophones. Semangat belajar bahasa Prancis tampaknya didukung oleh kesadaran para peserta akan potensi kunjungan wisatawan francophones ke Borobudur. Pembelajaran ini mereka andalkan sebagai "senjata" untuk berkomunikasi dengan para francophones dan untuk menarik minat mereka agar tinggal lebih lama di KHB serta menginap di homestay mereka.

\section{Pembuatan Video Dokumenter}

Pembelajaran bahasa Prancis ini juga didokumentasikan dengan baik dalam sebuah video. Video dokumenter ini menjadi salah satu luaran dalam rangka penyempurnaan laman dan brosur tentang KHB.

Untuk mendukung promosi KHB di dunia maya sehingga menarik lebih banyak wisman francophones, dilakukan penyempurnaan laman dan brosur tentang aktivitas di kampung ini dalam bahasa Prancis. Dengan isi laman dan brosur yang semakin menarik serta kekinian, diharapkan jumlah wisman francophones yang menginap di KHB semakin banyak.
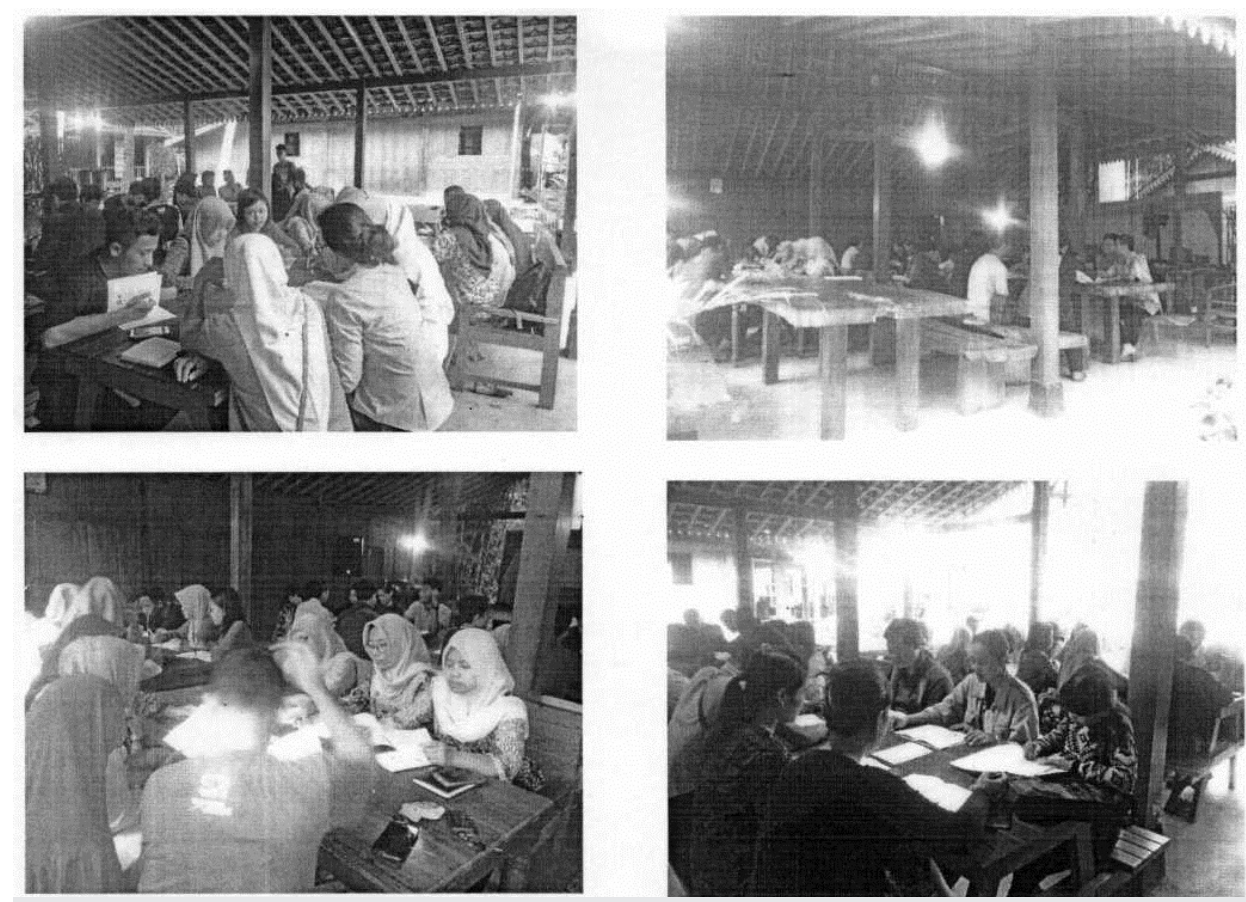

Suasana pelaksanaan kegiatan pengabdian kepada masyarakat di di pendopo Warung Kopi Borobudur, Dusun Ngaran, Borobudur. 


\section{Penutup}

Pengabdian berupa pembelajaran bahasa Prancis bagi para warga dan karyawan homestay berhasil mendatangkan optimisme bagi para peserta bahwa kini mereka sudah memiliki modal yang cukup kuat untuk menarik lebih banyak lagi wisman francophones agar memanfaatkan penginapan yang mereka tawarkan. Dengan tarif kamar yang sangat terjangkau dan terkoneksinya setiap homestay pada laman, situs-situs perjalanan, dan perhotelan daring, optimisme warga setempat jelas bukan tanpa alasan.

Jika tahun 2018 dan 2017 pengabdian Prodi Sastra Prancis FIB UGM difokuskan di KHB, Dusun Ngaran, Desa Borobudur, pada kesempatan yang akan datang akan sangat baik jika Prodi melakukan pengabdian di lokasi lain yang memiliki potensi pariwisata yang tinggi. Program semacam ini berjalan beriringan dan sejalan dengan banyaknya lulusan Prodi yang bekerja di sektor pariwisata. Di samping itu, program sejenis pun perlu dilanjutkan, ditingkatkan, bahkan diikuti oleh prodi bahasa asing lain guna mendukung pengembangan pariwisata Indonesia.

\section{Referensi}

Choudhury, Rahim Uddin. 2014. "The Rôle of Culture in Teaching and Learning of English as a Foreign Language». In Express, an International Journal of Multi Disciplinary Research. Vol. 1, Issue 4, April 2014.

Goodwin, Harold \& Rosa Santilli. 2009. "Community-Based Tourism: a Succès?", ICRT Occasional Paper 11. 